Etnográfica

Revista do Centro em Rede de Investigação em

Antropologia

vol. $14(3) \mid 2010$

Vol. $14(3)$

\title{
Redes de inclusão e burocracias de exclusão: riscos e seguros de responsabilidade civil entre os mais pobres na África do Sul
}

Inclusive networks and exclusive bureaucracies: risks and commercial insurance for the South African poor

\section{Erik Bähre}

\section{OpenEdition}

Journals

Edição electrónica

URL: https://journals.openedition.org/etnografica/256

DOI: 10.4000/etnografica.256

ISSN: 2182-2891

Editora

Centro em Rede de Investigação em Antropologia

Edição impressa

Data de publição: 1 outubro 2010

Paginação: 465-485

ISSN: 0873-6561

Refêrencia eletrónica

Erik Bähre, «Redes de inclusão e burocracias de exclusão: riscos e seguros de responsabilidade civil entre os mais pobres na África do Sul», Etnográfica [Online], vol. 14 (3) | 2010, posto online no dia 21 outubro 2011, consultado o 12 fevereiro 2022. URL: http://journals.openedition.org/etnografica/256 ; DOI: https://doi.org/10.4000/etnografica.256

\section{(c) (7) (8)}

Etnográfica is licensed under a Creative Commons Attribution-NonCommercial 4.0 International License. 


\title{
Redes de inclusão e burocracias de exclusão: riscos e seguros de responsabilidade civil entre os mais pobres na África do Sul ${ }^{1}$
}

\section{Erik Bähre}

\begin{abstract}
Nos últimos anos as grandes empresas da África do Sul têm vindo a criar uma variedade de apólices de seguro que visa abranger aqueles até então excluídos, na sua maioria não-brancos pobres e de classe média. Neste artigo analiso as definições de custos e riscos, bem como a tentativa de poupar custos contando com o capital social dos mais pobres. Esta análise trará uma nova dimensão aos já acesos debates em torno do risco, desigualdade e capital social. A pesquisa levada a cabo junto de clientes que habitam em townships da Cidade do Cabo, bem como de correctores de seguros, actuários e outros envolvidos no mundo dos seguros, demonstra de que forma os custos das apólices estão directamente relacionados com a grande variedade de riscos e adversidades a que os mais carenciados estão sujeitos. Demonstra ainda o modo como as seguradoras mobilizam o seu capital social para ganhar acesso a novos mercados - por vezes com consequências desastrosas - e têm, em simultâneo, uma complexidade burocrática que dificulta o recebimento das compensações por parte dos clientes. Este estudo sugere, contra-intuitivamente, que a rápida expansão do mercado dos seguros pode agravar os riscos a que os mais pobres estão expostos e aumentar as desigualdades.
\end{abstract}

PALAVRAS-CHAVE: África do Sul, apólices de seguros, risco, pobreza, redes sociais, marketing.

l Este estudo foi financiado em grande parte pela NWO-WOTRO e levado a cabo sobretudo na AMIDSt, Universidade de Amesterdão. É ainda parte do projecto "Investing, engaging in enterprise, gambling and getting into debt: popular economies and citizen expectations in South Africa" na London School of Economics, financiado pela ESRC (RES-062-23-1290). Quero agradecer a Susana Narotzky pelos seus valiosos comentários a uma primeira versão deste artigo durante a Ethnografeast III. Quero agradecer também a Catarina Frois pela tradução para português do original em inglês. 
INTRODUÇÃO: GLOBALIZAÇÃO, DESIGUALDADE E RISCO

De acordo com o influente guru da gestão empresarial, Prahalad, a globalização e o neoliberalismo podem contribuir para atenuar a pobreza e diminuir a desigualdade. Em Fortune at the Bottom of the Pyramid (2004), Prahalad dá exemplos desta situação em que todos ganham. Ao globalizarem-se as empresas, afirma, pode contribuir-se para uma diminuição da pobreza e a criação de um desenvolvimento sustentável, na medida em que aquelas sejam suficientemente criativas na exploração de novos mercados. ${ }^{2}$

Idealmente, as seguradoras diminuem a pobreza e a desigualdade ao limitar as consequências de calamidades e adversidades. Neste sentido, o Banco Mundial criou em 2005 a Micro Insurance Agency e cada vez são tomadas mais iniciativas na área dos seguros dirigidos aos mais pobres. ${ }^{3} \mathrm{Na}$ teoria sociológica emergiu uma perspectiva bastante diferente sobre globalização e desigualdade. Especialmente relevante no estudo dos (micro)seguros é o seminal ensaio de Beck, Risicogesellschaft (1992 [1986]). Beck é um tanto pessimista acerca da capacidade dos seguros para lidarem com os riscos da modernidade reflexiva. ${ }^{4}$ $\mathrm{Na}$ sociedade do risco, a ordem global trata da alocação de recursos e da distribuição do risco. O autor sustenta que a importância da alocação e do controlo da riqueza para a configuração da sociedade está a desvanecer-se. Em vez da pobreza e da desigualdade, são os riscos - muitas vezes globais e provocados pelo homem - que conduzem a configurações sociais específicas.

As desigualdades não desaparecem de todo. Elas apenas se redefinem de acordo com a individualização dos riscos sociais. O resultado é que os problemas sociais são cada vez mais entendidos em termos de disposições psicológicas: como inaptidões pessoais, sentimentos de culpa, ansiedades, conflitos e neuroses. (Beck 1992 [1986]: 100)

Que material empírico temos e de que forma se relaciona com tão diferentes perspectivas - o cenário fatalista de Beck versus o optimismo expressado pela indústria dos micro-seguros - sobre a globalização económica, a desigualdade e o risco? A África do Sul é conhecida pelos seus altos níveis de risco e tem um mercado de seguros que se estende às populações mais vulneráveis da sociedade, proporcionando um conhecimento único das dinâmicas da desigualdade, do risco e da globalização. Até que ponto são justificadas as expectativas de

2 Para uma análise histórica da moralidade da economia colonial, ver Burke (1996).

3 Ver também <http://www.microfinancegateway.org/resource_centers/insurance>. Ver ainda as Metas para o Desenvolvimento no Milénio, rubrica número oito sobre mercados financeiros. Para uma análise crítica da relação entre neoliberalismo e microfinança, ver Elyachar (2002).

4 Ver Ericson e Doyle (2004), para um estudo de caso que revela a resistência dos seguros perante o terrorismo global. 
organizações para o desenvolvimento, segundo as quais esses seguros, através da mitigação de riscos, podem diminuir a desigualdade? Até que ponto podemos destrinçar os riscos da desigualdade, e quais são as consequências da possível divergência nos padrões de redistribuição, tais como os previu Beck?

O exemplo sul-africano revela que é crucial examinar de perto as várias maneiras como o risco é definido e quais as consequências destas definições para as seguradoras. Esta abordagem é inspirada pela estimulante análise de Ewald sobre a construção histórica e social do risco e dos seguros em França (Ewald 1986, 2002). Enquanto o risco e os seguros no século XIX tinham a ênfase na "providência" e no século XX na "prevenção", entrámos agora numa era dominada pelo princípio da "precaução": "A precaução, tal como a vemos emergir hoje, centra-se [...] na incerteza - a incerteza do próprio conhecimento científico" (Ewald 2002: 293).

Como são concebidos o risco e os seguros na África do Sul e qual é a relevância destas definições quando os seguros são vendidos aos mais pobres de um dos países com maior desigualdade no mundo?

Até que ponto se adequa o conhecimento científico quando aplicado ao segmento mais baixo do mercado? Até agora, os sinais não têm sido muito satisfatórios, quanto mais não seja pelo papel central que o capital social desempenha nos esforços das seguradoras para tornarem os seus produtos disponíveis para os mais carenciados. Para a microfinança, o capital social tornou-se central para chegar aos mais pobres. Espera-se que as relações comunitárias, os valores e as normas partilhadas e a confiança funcionem como colaterais não convencionais e como cruciais na capacidade de os mais pobres terem acesso a serviços financeiros. ${ }^{5}$ Mas quem é que está a ter acesso a quem? São os mais pobres que realmente têm acesso a propostas de seguro que contribuem para uma existência sustentável, ou são os fornecedores de serviços financeiros que conseguem de forma eficaz ter acesso aos mais pobres, de maneira a vender os seus produtos? Por um lado, as companhias de seguros assentam em grande medida no capital social, enquanto, por outro lado, se apoiam nos seus próprios procedimentos burocráticos.

A moralidade das seguradoras nos Estados Unidos girava em torno da capacidade de estabelecer o preço de uma vida, como mostra a pesquisa de Zelizer sobre as apólices funerárias no século XIX, ou das flutuações do valor produtivo e sentimental das crianças (Zelizer 1994). Na África do Sul, contudo, os debates em torno da moralidade dos seguros centram-se nos efeitos dos seguros sobre as redes sociais e sobre as relações entre os mediadores de seguros, os clientes e os seus dependentes.

5 Para uma análise detalhada deste debate, bem como resultados etnográficos respeitantes ao capital social e à gestão financeira informal, ver Bähre (2007b). 


\section{RISCO E SEGUROS NA ÁFRICA DO SUL}

A África do Sul é uma sociedade com enormes riscos, em especial para as populações urbanas mais pobres. A sida espalha-se a uma velocidade galopante e algumas estimativas indicam que quase $30 \%$ da população está infectada com HIV. ${ }^{6}$ São sobretudo os mais pobres e a classe média-baixa que têm de viver numa situação de medo de serem roubados, assassinados, agredidos ou violados. A África do Sul apresenta as mais altas taxas de assassinato e homicídio, de criminalidade violenta e violações participadas. ${ }^{7}$ A falta de confiança no Estado, resultado, em parte, de uma polícia e de um sistema judicial ineficazes, mas também uma herança do apartheid, só vem aumentar o alto nível de risco (Bähre 2007a).

Para os residentes de áreas urbanas como a Cidade do Cabo, a polícia é, pura e simplesmente, algo de que não dispõem. ${ }^{8}$ Para as pessoas mais vulneráveis, sobretudo negros, a exposição a situações de perigo de vida tornou-se parte do quotidiano. No ano de 2002, "dois em cada três lares negros das townships da Cidade do Cabo não tinham o suficiente para se alimentarem" (BBC 2003). ${ }^{9}$ A sida, a violência e a perda de rendimentos afectam muita gente: os membros do agregado familiar tomam conta dos doentes à custa dos próprios salários, as dívidas acumulam-se devido aos custos dos funerais e as pessoas estão traumatizadas pela doença e morte dos que lhes são próximos. As principais causas de morte entre os negros na Cidade do Cabo são o HIV/SIDA e a tuberculose (39\%), bem como a agressão física (29\%) (BBC 2003). O aumento dos riscos transforma riscos idiossincráticos em riscos colectivos que minam a capacidade das pessoas e instituições para os gerir.

A segurança social garantida pelo Estado é limitada, embora seja mais estruturada do que noutros Estados africanos. ${ }^{10}$ Os hospitais estatais oferecem cuidados médicos pouco dispendiosos, mas de fraca qualidade, e o governo gere pensões de reforma e de invalidez parcas e mal distribuídas. ${ }^{11}$ Mas o alto nível

6 Com base em testes pré-natais no final do ano de 2004, 29,5\% da população já está infectada pelo HIV. Ver também <http://www.avert.org/safricastats.htm>, sobre a fiabilidade destas estatísticas.

7 Veja-se <http://www.nationmaster.com>. A Colômbia apresenta-se em primeiro lugar nos "homicídios voluntários". A África do Sul está em primeiro lugar em todos os outros tipos de homicídios e assassinatos.

8 Em pelo menos uma zona residencial da Cidade do Cabo, a polícia chegou mesmo a fechar as suas esquadras por serem constantemente vandalizadas. Mudaram as esquadras para contentores comerciais que fechavam durante a noite.

9 O termo township, na África do Sul, designa áreas segregadas na periferia das cidades onde durante o apartheid residiam os não-brancos; actualmente, aí residem os mais pobres.

10 Ver Dietz e Foeken (2001), sobre a fragilidade financeira dos Estados africanos.

11 "Em 1995/96, cerca de 60\% do total nacional do orçamento da segurança social eram gastos em pensões de reforma/velhice" (Sagner e Mtati 1999: 398). Sobre a corrupção na distribuição destes recursos, veja-se também Brown (1998). Estes escassos recursos podem ser tão vitais para a sobrevivência que uma mulher tentou contrair sida propositadamente, de maneira a poder reclamar [continua] 
de pobreza e os riscos a que muitos estão expostos implicam que seja muitas vezes necessário pedir ajuda à família e aos vizinhos. As remessas de dinheiro de familiares a trabalhar em áreas urbanas para os seus familiares mais necessitados a viver em áreas rurais são uma prática comum que foi reforçada com a política do apartheid (Bähre 2007a; Bank 1999; Sharp e Spiegel 1985). Para além disso, os mais pobres a viver nas cidades organizam diversas associações de socorros mútuos como as sociedades de apoio a funerais, que desempenham um papel vital na distribuição de recursos dentro das redes familiares. ${ }^{12}$ Estas estruturas de apoio são importantes, embora também inadequadas quando considerados os muitos riscos a que os mais pobres estão expostos. Ainda que as relações sociais, sobretudo entre familiares, sejam cruciais para atenuar as crises que os mais pobres atravessam, não devem ser idealizadas ou romantizadas (Bähre 2007b). Mas, na ausência de alternativas, as relações sociais são muitas vezes a única forma de lidar com os riscos (cf. Dercon 2002; Von Benda-Beckmann e Von Benda-Beckmann 1994; Leliveld 1994, 1997).

Contudo, nos últimos anos, formas alternativas de lidar com os riscos estão a generalizar-se entre os empregados domésticos, os seguranças privados e os funcionários públicos das categorias mais baixas. As grandes companhias de seguros sul-africanas, tais como a Sanlam, a Old Mutual, a Metropolitan e a Liberty Life, têm vindo a expandir os seus negócios à população negra, sobretudo às famílias mais pobres e à classe média-baixa. Estas empresas têm vindo a criar uma variedade de planos de seguros dirigidos aos mais pobres, anteriormente excluídos. Por exemplo, David Porteous, fundador e director da Bankable Frontier Associates, apercebeu-se da existência de um enorme mercado para os seguros dentro do segmento mais pobre da sociedade, a faixa que vai de um a cinco na escala Living Standard Measure (LSM). Numa intervenção apresentada à DFID, Porteous (2005) identifica quase nove milhões de unidades domésticas das quais apenas $8 \%$ têm um seguro funerário. Para os seguros de funerais na África do Sul, Porteous identifica um segmento para a criação e o desenvolvimento de um mercado com mais de seis milhões de unidades familiares, quase dez vezes o mercado existente (Porteous 2005). Perspectiva-se um vasto mercado. ${ }^{13}$ Os mediadores de seguros estão a vender apólices, que vão desde seguros de vida a seguros que cobrem o roubo de propriedade; visitam os mais pobres nas suas casas, abordam transeuntes nas filas de táxis e nas estações de comboios, ou oferecem pacotes de apólices através dos empregadores. As companhias de seguros também colaboram com organizações já existentes,

uma pensão de invalidez de 180 rands (23 euros) por mês (comunicação pessoal do Dr. Isak Niehaus, a 30 de Junho de 2003 no Lowveld sul-africano).

12 Ver Bähre (2007a) e Delius (1993), sobre a história das sociedades mútuas de funerais.

13 Ver o influente Fortune at the Bottom of the Pyramid de Prahalad (2004), sobre marketing para os mais carenciados. 
como as igrejas, sociedades mútuas de apoio a funerais, sindicatos e funerárias locais, na tentativa de atrair novos clientes.

Entre outros, os fornecedores de serviços financeiros assinaram a Financial Sector Charter on Black Economic Empowerment. Nesta Carta de Princípios, o sector financeiro compromete-se a aumentar o número de não-brancos em cargos superiores, a apoiar o estabelecimento de pequenas e médias empresas detidas por negros, bem como a tornar mais fácil o acesso dos mais pobres a produtos financeiros (Financial Sector Charter). ${ }^{14}$

Enquanto a pobreza e a violência colocam as instituições estatais e as relações sociais, em particular as relações de parentesco, sob forte pressão, estes novos seguros capacitam as pessoas mais pobres para gerir os riscos de formas inconcebíveis até agora - pelo menos, esta é a expectativa que criam. Esta combinação de redes sociais com burocracia é uma prática globalizada. ${ }^{15}$ As companhias de seguros a nível mundial dependem em grande parte das redes de agentes e organizações intermediárias para estabelecer e manter relações com os clientes. O que é específico dos seguros na África do Sul são os níveis quase sem precedentes de risco e desigualdade. Quais são as consequências destes altos níveis de risco e desigualdade na maneira como as seguradoras visam o segmento mais baixo do mercado, como os agentes de seguros gostam de se referir aos residentes negros assolados pela pobreza? A África do Sul é também única porque, ao contrário de outros países em desenvolvimento, tem um sector de seguros muito forte. A penetração deste sector na economia é estimada em 14,5\% do PIB, um valor bastante alto quando comparado com o de muitos outros países em desenvolvimento, como a Indonésia $(1,19 \%)$ e a Índia $(0,62 \%)$, mas também quando comparado com o dos Estados Unidos (5,23\%). ${ }^{16}$ Contudo, a despesa pública é distribuída de forma desigual entre a população.

\section{DOS RISCOS AOS CUSTOS}

Quando entrevistei actuários a trabalhar no sector de seguros na África do Sul, previa que a discussão andasse à volta da avaliação do risco. Os sul-africanos estão expostos a muitos riscos, sobretudo os mais pobres, o que torna estes cálculos cruciais. Além disso, esperava que os dados actuariais para calcular os riscos fossem limitados, uma vez que este era um mercado relativamente recente. Outras fontes de dados, tais como as fornecidas pelo Instituto Sul-Africano

14 Disponível em < http://www.treasury.gov.za/press/other/2003101701.pdf>.

15 No seu estudo sobre a microfinança no Egipto, Elyachar (2002) defende que as redes sociais informais e as comunidades estão no centro do desenvolvimento económico neoliberal.

16 O valor para a África do Sul é indicado no relatório das seguradoras Q4 2004 (Business Monitor International, Londres, Mermaid House, p. 3). A informação sobre outros países foi retirada de um estudo feito pelo Insurance Information Institute sobre os gastos com seguros não-pessoais em 2003 (ver < http://www.marginalrevolution.com/marginalrevolution/2005/02/insurance_fact_html >). 
de Estatística, gozavam da reputação de serem muito pouco fiáveis, sobretudo no que dizia respeito a assuntos sensíveis como a prevalência do HIV. Estas circunstâncias tornavam muito complexo avaliar os riscos a um nível agregado. Neste sentido, eu esperava que as conversas com actuários fossem centradas nas formas alternativas de avaliação dos riscos (ver Ericson e Doyle 2004).

Os debates com estes profissionais, contudo, foram sobretudo focados nos custos e não tanto nos riscos. Apesar de ser um desafio avaliar o risco deste novo mercado de clientes de extrema pobreza, os custos eram uma preocupação muito maior. ${ }^{17} \mathrm{~A}$ distinção entre risco (complexo mas viável) e custo (o maior desafio para este mercado) foi-se tornando cada vez mais clara.

Explicaram-me que o prémio que os segurados pagavam consistia em três partes: uma parte destinava-se ao lucro (que não será estudado aqui), outra parte tinha de cobrir o risco, e a outra parte de cobrir as despesas. De maneira a tornar as apólices de seguros acessíveis, estas tinham por norma pouca cobertura. Um exemplo típico é o da cobertura de "morte acidental", uma das apólices mais baratas e mais populares em meios de pobreza. O risco que a apólice cobria era muito limitado. Cobria apenas a morte acidental, isto é, a que não resultasse de suicídio, assassínio, velhice, saúde debilitada ou comportamento negligente. $\mathrm{O}$ montante que os descendentes do segurado iriam receber estava normalmente estipulado em 10.000 rands, aproximadamente 1000 euros. Riscos limitados e compensações limitadas diminuem o prémio mensal que os clientes têm de pagar. A maior parte das apólices que são vendidas aos mais pobres refere-se a seguros de funeral de valores relativamente baixos, apólices que cobrem a perda ou furto de telemóveis, seguros de acidentes pessoais, bem como apólices que cobrem dívidas que não foram pagas devido a doença prolongada. Seguros de saúde com cobertura alargada ou cobertura de desemprego são normalmente demasiado dispendiosos, devido aos riscos elevados e benefícios dispendiosos que representam. O resultado é que, mesmo quando os grupos que têm poucos rendimentos ou que são mais desfavorecidos contraem estas apólices, os riscos que elas cobrem são bastante reduzidos. As apólices de seguro tornam-se mais acessíveis pela diminuição da cobertura, pela definição de cláusulas de exclusão e pela agregação dos riscos. De forma inevitável, as apólices mais baratas cobrem apenas pequenos riscos. Para venderem seguros de modo eficaz aos mais pobres e à classe média-baixa, as companhias de seguros restringiram os riscos cobertos pelas apólices.

Menos flexíveis e mais problemáticos para as seguradoras eram os custos das apólices destinadas a estes grupos. Mesmo quando uma apólice tinha algum sucesso, a parte do prémio usada para cobrir os custos ultrapassava largamente

17 Em várias entrevistas, os actuários notaram que mesmo a pandemia HIV/SIDA não era uma grande preocupação no que respeitava ao cálculo de riscos. Pergunto-me até que ponto é mesmo assim ou se era apenas um discurso de relações públicas. Este será um tema que voltarei a retomar. 
o montante destinado a cobrir os riscos. Ao passo que os custos não representavam grande problema com clientes de maiores rendimentos, tornavam-se cruciais para o sucesso das apólices destinadas aos mais pobres. Em primeiro lugar, porque as apólices comercializadas entre a classe média-baixa e os mais pobres cobriam riscos relativamente baixos, ao passo que o montante associado à gestão das apólices era relativamente alto. Muitos dos custos associados à gestão administrativa são independentes do tipo de apólice. Uma apólice, seja o prémio mensal de 1000 ou 100 rands, tem de ser processada a nível administrativo, as garantias bancárias têm de ser verificadas, tem de haver quem passe e envie os cheques, as ordens de débito têm de ser processadas, os call centers têm de ter os seus funcionários, e por aí fora. Estas despesas administrativas representam uma percentagem significativa do prémio mensal de uma apólice pequena. Em segundo lugar, pela própria natureza da sua vulnerabilidade às adversidades, os clientes mais pobres e com rendimentos reduzidos são muito mais propensos a cancelar as suas apólices do que os clientes mais abastados, e isto representa também custos acrescidos. No final de Janeiro de 2006, a Life Offices Association (LOA, a associação de companhias de seguros de longa duração da África do Sul) fez um comunicado à imprensa sobre a provisão de produtos de seguros de vida dirigidos a pessoas com rendimentos inferiores a 3000 rands. "O objectivo da LOA para 2014 é reforçar a penetração para 180\% dos níveis actuais (i.e., para 3,8 milhões de apólices), tarefa que não é fácil, tendo em conta o vasto número de apólices que por norma cessam anualmente." 18

Os salários e as comissões dos agentes de seguros, o peso administrativo inerente à criação das apólices, os custos das transacções financeiras, bem como o facto de as pessoas com menos rendimentos serem muito mais propensas a cancelar as suas apólices, por vezes num período de meses após a adesão, representam um problema considerável. De maneira a vender apólices a estes clientes, os agentes de seguros tiveram de encontrar formas de reduzir ao máximo os custos administrativos. Para o fazer, as companhias de seguros contam cada vez mais com as redes sociais. Para explicar como funcionam os intermediários e o modo como isto se relaciona com a definição dos custos, será útil distinguir entre corretores de seguros e organizações intermediárias.

\section{CORRECTORES DE SEGUROS}

Todas as grandes seguradoras sul-africanas criaram departamentos específicos para reforçarem o seu mercado junto dos mais pobres e da classe média-baixa. Algumas companhias abriram escritórios nos municípios onde vivem africanos e pessoas de cor e contrataram vendedores de seguros residentes nestas áreas. 
Estes vendedores (sempre homens, não encontrei nenhuma mulher nesta função) visitam as pessoas nas suas casas, abordam-nas nas paragens de táxi e estações de comboios, fazem apresentações dos seguros em escolas, esquadras de polícia, centros médicos e mesmo em bases militares. O corrector de seguros instala um projector ou coloca cartazes nas salas dos funcionários e explica-lhes os seus produtos (sobretudo apólices de funerais, aplicações financeiras, poupança-reforma, seguros de cobertura de educação dos filhos e netos) e quais os benefícios associados. Estas apresentações não são apenas ocasionais. Vários professores disseram que recebem a visita de um corrector de seguros pelo menos uma vez por mês, enquanto há uns anos nunca teriam tido um agente de seguros a visitar a sua escola. Os professores, por vezes, assistem a estas demonstrações com atenção, mas geralmente continuam a almoçar, a corrigir testes e a conversar com os colegas.

A forma como estes seguros são vendidos faz lembrar as vendas directas de organizações como a Tupperware nos Estados Unidos, que se tornou tão popular durante a depressão nos anos de 1930. Estas organizações de venda directa, como mostrou Biggart (1989), eram mais populares do que outras porque limitavam os custos com o emprego. Para as seguradoras da África do Sul, os custos associados à contratação de funcionários representavam uma preocupação. O rendimento dos mediadores de seguros provinha em grande medida das comissões que recebiam. Normalmente, a sua comissão representava $85 \%$ do prémio anual. As seguradoras estavam acostumadas a vender apólices relativamente avultadas a pessoas com rendimentos consideráveis e que dificilmente cancelariam as suas apólices, o que representava um rendimento razoável para os correctores. Contudo, hoje em dia as apólices são vendidas a clientes predominantemente não-brancos e pobres. As apólices podem ter prémios de apenas 10 rands por mês, o que significa que os agentes receberão uma comissão de apenas 100 rands.

Durante as entrevistas com detentores de apólices residentes em townships da Cidade do Cabo, tornou-se claro que, para eles, as apólices não eram frequentemente uma prioridade. Confrontados com problemas financeiros, era muito comum cancelarem-nas. Por vezes também se revelava difícil recusar fazer uma apólice em virtude da relação que se tinha com o corrector, habitualmente um vizinho, um parente ou um membro da mesma igreja. Como um destes clientes me explicou: "Ele [o corrector] foi-me apresentado por uma pessoa da igreja e veio falar comigo. Fiz um seguro mas não precisava realmente dele, por isso cancelei-o ao fim de alguns meses." Ao fornecer informação bancária falsa, cancelar rapidamente o seguro ou dar os dados de uma conta onde não há dinheiro disponível, uma pessoa pode cancelar a apólice sem ter de o dizer ao seu mediador, que se verá privado do seu rendimento.

Um dos mediadores disse-me como sentiu que tinha sido aliciado enganosamente a vender apólices. Era um homem com uns 35 anos que veio de 
East London; quando o entrevistei tinha-se mudado há pouco tempo para uma barraca nas imediações da township de Philippi, na Cidade do Cabo. Em East London, estava empregado como gerente de hotel e, um dia, um recrutador de uma companhia de seguros veio ter com ele ao trabalho. $\mathrm{O}$ angariador disse-lhe que podia ganhar muito mais dinheiro do que estava a receber na altura, que teria uma vida muito mais fácil se fosse trabalhar para eles. Poderia ganhar 12.000 rands mensais, comprar um belo carro e viver muito melhor do que até então. Ele não gostava do trabalho que tinha e a perspectiva de se tornar um mediador parecia-lhe boa, por isso largou o emprego como gerente de hotel e assinou um contrato com a companhia de seguros. O contrato estipulava que iria receber formação durante cinco meses. Os primeiros três meses seriam de formação a tempo inteiro e receberia 5.000 rands por mês. Nos restantes dois meses teria de começar a vender apólices e receberia um ordenado com base nas comissões. Mas, como ainda não teria experiência, ganharia na mesma um salário de 2500 rands no quarto mês e de 1500 rands no quinto mês. A partir daí, as comissões deveriam dar-lhe dinheiro suficiente. Além disso, tinha de trabalhar para a seguradora pelo menos durante um ano. Se rescindisse o contrato, tinha de repor os 19.000 rands que tinha recebido nos primeiros cinco meses do contrato. Esta cláusula está incluída para evitar que os correctores mudem para a concorrência logo após a seguradora ter investido na sua aquisição de competências.

$\mathrm{O}$ meu entrevistado fez a formação e, quando esse período terminou, a empresa organizou um churrasco para os formandos. Esta foi a primeira vez que teve contacto com outros representantes de vendas da região. Quando chegou ao local onde se fez o churrasco, explicou-me, começou a duvidar do futuro idílico que lhe tinham prometido. Considerando os elevados rendimentos que supunha vir a receber, estava à espera de encontrar carros luxuosos à entrada. Mas não encontrou limusinas, e sim carros velhos e enferrujados. Mesmo o carro do melhor vendedor da região era modesto, não muito diferente do seu próprio carro na altura. Quando começou a vender apólices, tornou-se claro que não conseguiria ganhar 12.000 rands; em vez disso, disse-me que apenas conseguia fazer 5.000 rands por mês, mais ou menos o mesmo salário que tinha como gerente de hotel. Disse-me que alguns dos seus colegas ganhavam bastante mais, cerca de 12.000 rands por mês, mas muitos outros recebiam ainda menos que ele. Explicou-me que o final do mês era muito embaraçoso:

Juntávamo-nos e o gerente mostrava [num quadro] quantas apólices tinham sido vendidas por cada um e o melhor vendedor era elogiado e considerado como um modelo a seguir. Mas durante estas reuniões também se tornava claro que alguns colegas não tinham vendido nem sequer uma apólice. Eu sentia mesmo pena deles porque não receberiam dinheiro nenhum. Às vezes um colega vinha ter comigo e dizia-me: "Podes-me emprestar algum dinheiro?" Tu sabes que eles têm uma família para alimentar e não têm 
salário, mas também hesitas em emprestar dinheiro. Alguma vez o vais receber de volta?

Apesar de alguns colegas não ganharem nada, não podiam deixar o emprego e procurar outro, uma vez que teriam de restituir os 19.000 rands. De facto, o contrato elaborado pela companhia de seguros assemelhava-se a um trabalho forçado.

Este ex-vendedor também se queixava das despesas que tinha de fazer. Tinha de pagar o seu próprio carro, pagar o combustível e o telemóvel; tinha até de comprar pequenos brindes - como, por exemplo, canetas com o logótipo da empresa - com o seu próprio dinheiro. O gerente da filial incentivava, quase exigia, que todos os mediadores pusessem de parte algum do seu rendimento. Este dinheiro seria colocado numa conta pessoal controlada pelo gerente e seria utilizado por ele para comprar canetas, $t$-shirts e outros brindes da empresa.

Para além das pressões financeiras, o meu entrevistado queixava-se veementemente das pressões sociais com que tinha de lidar. Para conseguir vender apólices tinha de mobilizar de forma agressiva as suas redes sociais. Enquanto as organizações norte-americanas de venda directa assentavam num vocabulário de parentesco (Biggart 1989), as companhias de seguros sul-africanas abordam os novos clientes com um vocabulário de comunidade, falando de planos comunitários e de grupo. Este mediador, como muitos outros, visitava os residentes do seu bairro, bem como de bairros onde tinha vivido anteriormente ou onde conhecia pessoas. Assistia ao maior número de funerais possível e tentava vender apólices aos que estavam presentes. Quando falámos sobre isto, ele ainda se sentia um pouco embaraçado por usar os funerais para vender os seus seguros. Nessas alturas dizia coisas como: "Não é triste morrer e deixar a família com nada excepto a preocupação de como pagar o funeral? Um seguro de funeral tira-lhe mesmo este fardo de cima." Então dava-lhes um panfleto e tentava encontrar-se com eles mais tarde. Visitava-os na igreja que frequentavam e procurava conhecer mais pessoas através da congregação.

O resultado destas diligências, explicou, era que toda a gente esperava que ele fizesse toda a espécie de favores: "Sabes como é que as pessoas são. Pensam que estás a ganhar uma data de dinheiro com eles e querem ter algum proveito. Então tens de os ajudar, caso contrário a tua reputação vai pelo cano abaixo." Recebia chamadas dos clientes a pedirem favores como: "Podes levar os meus filhos à escola? Não tenho dinheiro para os transportes"; "Podes vir buscar-me e levar-me à cidade? Preciso de ir às compras." Cerca de metade do seu dia era gasto a levar pessoas ou a ajudar os seus clientes a resolver problemas financeiros com bancos ou companhias de seguros, mesmo quando estes problemas não tinham nada a ver com o seu trabalho ou a companhia para a qual trabalhava. Se se recusava a ajudar, temia que os seus clientes falassem sobre ele nas suas costas e isso tornasse muito difícil vender apólices. Estava a ficar farto de todos 
estes pedidos. Quando numa altura o seu carro se avariou e não tinha dinheiro para o mandar reparar ou comprar outro, tornou-se ainda mais complicado ganhar a vida. Exactamente ao fim de um ano, nem mais um dia, demitiu-se. Não tinha outro emprego, mas queria sair dali desesperadamente. Em pouco tempo saiu de East London e mudou-se para a Cidade do Cabo à procura de emprego. Mas o trabalho não era a única razão para se mudar para a Cidade do Cabo. Também queria afastar-se das pessoas de East London, que continuavam a aborrecê-lo com os seus problemas financeiros e esperavam que os ajudasse a resolvê-los, a escrever cartas, a fazer telefonemas, ir aos bancos e às companhias de seguros, e por aí adiante. Para os seus amigos, vizinhos, membros da mesma igreja, familiares e conhecidos, ele tinha-se tornado o perito financeiro a que recorriam. Para escapar a estas pressões sociais mudou-se para a Cidade do Cabo. Depois de quase um ano desempregado, conseguiu trabalho como gerente de um restaurante.

Alguns dos actuários e outros a trabalhar no sector dos seguros disseram-me que as seguradoras sabiam que havia problemas com os mediadores, sobretudo os que trabalhavam em zonas precárias. Contudo, entendiam o problema de maneira muito diferente da minha e pareciam estar completamente alheados, ou desinteressados, do facto de muitos dos mediadores trabalharem em condições que em muito se assemelham a trabalho forçado. O problema que enfrentavam era que, por vezes, os mediadores recorriam a meios ilegais para vender apólices e receber a sua comissão. Havia vários rumores e também alguns relatos de agentes de seguros que mentiam aos clientes sobre as apólices que vendiam, ou omitiam informação essencial sobre as condições das apólices. Reter esta informação era fácil quando lidavam com clientes iletrados. $\mathrm{Na}$ tentativa de ganhar dinheiro, os representantes de seguros por vezes tornavam-se demasiado insistentes e o medo das pessoas que trabalham neste ramo era que estes incidentes ameaçassem a sua reputação.

Quando disse às pessoas dentro da área que, quando se aplica o sistema de comissões a um universo de clientes pobres e iletrados, eles frequentemente cessam as suas apólices, a resposta normal era que estavam cientes deste problema, mas estas eram situações criadas pelas chamadas "empresas-fantasma": empresas ilegítimas que tentavam ganhar dinheiro à custa dos clientes. As seguradoras de grande dimensão e bem estabelecidas, asseguraram-me, não eram responsáveis. Esta afirmação não se reflectia nas entrevistas que tive com clientes que viviam em townships da Cidade do Cabo, nem nos resultados da análise dos provedores de justiça para os seguros a longo-prazo (Nienaber e Preiss 2006). Apesar disso, muitos dos que trabalhavam neste ramo preocupavam-se com os danos que estas "empresas-fantasma" poderiam causar na reputação de todo o sector. O problema da vulnerabilidade dos rendimentos em que o sistema de comissões colocava os agentes de seguros, em especial aqueles que tentavam vender seguros a negros, nunca foi mencionado. 
No final de 2005, algumas seguradoras começaram a rever o seu sistema de comissões. Em resultado, um crescente número de companhias de seguros mudaram o sistema de pagamento aos mediadores. Em vez ser paga a totalidade depois de a apólice ser comprada, os mediadores recebem a sua comissão ao longo de um período de vários anos, dependendo do tempo de permanência do cliente. Isto só agravou a situação já desesperada destes mediadores. Uma vez que muitos agentes abandonam o trabalho após um ano, nem sequer chegam a receber todo o dinheiro a que têm direito.

Quando os clientes querem participar um sinistro, frequentemente vão ter com os seus mediadores e esperam ser ajudados. Por vezes estes mediadores conseguem ajudá-los, preenchendo um impresso ou fazendo um telefonema para os escritórios. Contudo, os mediadores não são pagos por este serviço e as minhas entrevistas com detentores de apólices revelaram que é frequente ficarem frustrados com a incapacidade, ou má vontade, dos seus mediadores quando se trata de ajudar. A rede social, que era tão fundamental para vender a apólice, não pode ser mobilizada para receber os benefícios. Ao invés, os clientes têm de telefonar para números gratuitos onde não é excepção que não consigam ser atendidos na sua língua materna. Precisam de enviar documentos por fax, apesar de em áreas urbanas como a Cidade do Cabo a máquina de fax mais próxima poder chegar a estar a uma hora de caminho.

Uma mulher explicou-me que estava a tentar receber as compensações há já mais de um ano. Nada funcionava e a sua participação, na minha perspectiva, legítima, era recusada repetidamente, ou simplesmente ignorada. Finalmente, decidiu ir pessoalmente ao escritório da seguradora e falou com uma consultora que prometeu resolver-lhe a situação. Para conseguir resolver o problema, a consultora tinha de ter os documentos originais da apólice e a mulher entregou-lhos. Depois de algumas semanas telefonou para a seguradora e foi-lhe dito (por outra consultora) que não tinha direito a quaisquer compensações. Fosse como fosse, disse-lhe a senhora ao telefone, ela tinha estado nos escritórios na semana anterior e cancelado a apólice. Não podia reclamar compensações de uma apólice cancelada. Isto, claro, enfureceu a cliente, mas já não havia nada a fazer.

As organizações de provedoria dos clientes são também igualmente burocratizadas e, em grande medida, apenas acessíveis para a elite. Qualquer provedoria no sector financeiro só aceita casos escritos em inglês. Independentemente disso, recebem várias reclamações que demonstram o tratamento injusto que alguns clientes recebem (Nienaber e Preiss 2006). Num discurso para a Life Offices Association, o provedor afirmava o seguinte:

Bom, há uma coisa que podemos dizer sobre as seguradoras e o seu material de marketing: passam uma imagem de ajuda e assistência, a nata da bondade humana a fluir livremente em direcção a toda a humanidade, especialmente 
aos potenciais compradores de apólices. Mas eu desconfio, considerando as histórias que recebemos, que por baixo dessa fachada de benevolência bate também um coração de pedra. (Nienaber 2005: secção 13)

Porém, muitas destas queixas vêm de clientes relativamente abastados e instruídos. A situação problemática em que muitos vendedores de seguros se encontram, uma situação que é muitas vezes semelhante a trabalho forçado, não é de todo considerada.

\section{GRUPOS INTERMEDIÁRIOS}

Outra estratégia empregue pelas companhias de seguros para limitar os custos é a de recorrer à infra-estrutura de organizações intermediárias, tais como lojas de mobiliário, supermercados, agências funerárias, igrejas, e mesmo clubes de futebol, mas sobretudo sociedades mútuas de funerais. ${ }^{19}$ A vantagem, pelo menos na perspectiva das seguradoras, é ser muito mais barato usar a infra-estrutura financeira já existente do que construí-la de novo. Especialmente devido à herança do apartheid, é difícil encontrar alguma infra-estrutura financeira nas townships das maiores cidades, tais como a Cidade do Cabo ou Joanesburgo, mas também nos antigos bantustões, como os antigos Ciskei e Transkei. As companhias de seguros estavam especialmente interessadas em igrejas, agentes funerários e sociedades mútuas de funerais, mas também em vários outros grupos, como um clube de fãs de futebol ou um grupo coral. Contrariamente à maioria das organizações intermediárias geralmente usadas, como os sindicatos ou empregadores, estas organizações dão acesso a pessoas que não têm contratos de trabalho fixos. As companhias de seguros esperavam que estas organizações lhes permitissem chegar ao fundo do mercado e, em simultâneo, diminuir os custos associados a este segmento.

Por exemplo, falei com uma agente funerária em Gugulethu. Ela e o marido geriam o negócio a partir de casa e os vizinhos estavam entre os clientes mais importantes. Quando assumiram o negócio que pertencera ao pai dela, perceberam que ele tinha uma grande dívida com a casa funerária. Por diversas vezes, organizara funerais e tinha incorrido em despesas tais como comprar um caixão, enquanto os familiares não tinham chegado a pagar os custos do funeral. Foi um grande choque quando descobriram que o negócio da família estava a correr muito mal. Para ultrapassar o problema das contas por pagar, ela e o marido deram início a um fundo funerário comunitário. Todos os meses iam receber o prémio de porta em porta. Desta maneira, asseguraram uma clientela própria e diminuíram o risco das contas por pagar. Há um ou dois anos, houve 
companhias de seguros que a abordaram. Os representantes das seguradoras iam lá a casa convidá-la a cooperar com eles. A dada altura, decidiu trabalhar com uma seguradora sediada em Joanesburgo. Continuava a recolher dinheiro entre os vizinhos e outros membros da sociedade mútua de funeral, mas, em vez de pôr o dinheiro na sua própria conta bancária, transferia-o para a seguradora. Sempre que alguém morria, ela preenchia um formulário, anexava uma cópia da certidão de óbito e recebia um cheque da companhia de seguros com o qual assegurava o funeral. Esta prática é ilegal, visto que a agente funerária trabalha como uma intermediária financeira sem estar registada como tal, mas era mesmo assim prática corrente, também por parte de seguradoras comerciais de larga escala.

Os seus clientes não estavam a par desta mudança. Continuavam a considerar-se membros de uma sociedade mútua de funeral, mas na verdade eram tomadores de seguros. Ela explicou-me que quis manter segredo por recear que isso viesse a provocar desconfiança entre os seus clientes. Eu também suspeito que ela queria manter isto em silêncio porque assim não tinha de devolver aos clientes o cheque que recebia da seguradora, pois aqueles poderiam usá-lo para fazer o funeral com outra agência funerária ou decidir simplesmente nem sequer gastar o dinheiro com o pagamento do funeral.

Passado cerca de um ano, ela e o marido receberam uma carta que dizia que tinham feito demasiadas participações e o prémio iria subir. De facto, nos meses anteriores, tinham feito vários funerais. Tal não se devia apenas à idade avançada de alguns dos membros, mas também à alta incidência de criminalidade violenta, acidentes rodoviários e doenças como a tuberculose e o HIV na comunidade. A carta da seguradora estabelecia que, do mês seguinte em diante, o prémio subiria em 50\%. Ela disse-me que estava muito aborrecida por ter de cobrar mais $50 \%$ de prémio. Se não conseguisse, o contrato com a seguradora acabava e perderia tudo. Disse-me: "Como é que vou explicar às pessoas que têm que pagar mais metade do que já pagam? Como é que vou conseguir arranjar este dinheiro? Ninguém sabe sequer que trabalho com uma companhia de seguros!" Esta organização intermediária estava a lidar com pressões da seguradora que ameaçavam tanto o seu negócio de família como a reputação que tinham na zona onde residem há mais de 30 anos.

Uma história de sucesso referida várias vezes pelos mediadores de seguros é a da cooperação entre a seguradora African Life e a Zion Christian Church (ZCC). A ZCC é provavelmente a maior Igreja sul-africana, com 1100 congregações por todo o país, e é liderada pelo seu bispo com mão forte, estabelecendo fronteiras muito claras entre membros e não-membros, demarcadas pela indumentária e outras convenções sociais (ver Kiernan 1974). Não é permitido aos membros falar sobre a Igreja com pessoas de fora e têm de seguir uma rigorosa disciplina no que respeita ao vestuário, ao consumo de álcool e à participação nos encontros e outros eventos da Igreja. 
Durante muito tempo, as congregações da ZCC tinham as suas próprias sociedades mútuas de funeral mas apresentavam várias limitações. Por exemplo, se um membro da ZCC se mudava para outra região da África do Sul, normalmente à procura de emprego, tinha de começar de novo com a sociedade mútua da nova zona. Isto era muito inconveniente para os membros: as regras eram diferentes e as sociedades mútuas tinham muitas vezes um período de carência, ou seja, as compensações só podiam ser reclamadas depois de os prémios terem sido pagos durante meio ano. Para além disso, algumas congregações da ZCC não tinham uma sociedade mútua, enquanto outras a tinham mas não funcionava bem. Um novo plano nacional de apoio a funerais para todos os membros da ZCC iria resolver estes problemas. Independentemente das motivações práticas, um plano universal de apoio a funerais ajustava-se a uma Igreja já bastante hierarquizada e conduzida de forma centralizada. Apesar de nunca ninguém da ZCC ou da seguradora o ter afirmado, também podia ser uma maneira de a Igreja adquirir maior controlo sobre a situação financeira das suas congregações e dos seus membros. O bispo ficaria satisfeito por ter um conhecimento mais aprofundado da gestão financeira quotidiana das suas delegações. ${ }^{20}$

Em 1989, em conjunto com a African Life, a ZCC criou esse plano nacional de apoio a funerais exclusivo para os membros da congregação. Com o passar dos anos, esta iniciativa levou ao Kganya Group. O Kganya Group tornou-se responsável por gerir o plano, tratar da parte administrativa, fazer pagamentos à ZCC para que pudessem organizar o funeral, e também adicionou um seguro de acidentes pessoais que reembolsava na totalidade. Para além do seguro, a ZCC disponibilizou ainda outros serviços financeiros aos seus membros. O First Nacional Bank oferece a conta Kganya Card, uma conta à ordem exclusiva para membros da ZCC. ${ }^{21}$

O comité da delegação da ZCC recebe um prémio mensal de 23 rands $^{22}$ e deposita-o na conta da companhia de seguros. O comité também se encarrega da contabilidade e ajuda na organização do funeral. Um dos padres da ZCC que entrevistei, mas que não quer ser identificado porque na verdade precisava da autorização pessoal do bispo para conceder esta entrevista, disse-me que ele e outros membros da Igreja também davam apoio aos membros na participação de sinistros: ajudavam-nos a preencher os formulários, levavam-nos aos escritórios da Kganya e serviam de mediadores quando havia conflitos familiares sobre quem devia receber as compensações. Também organizavam velórios, serviços

20 Veja-se o argumento de Elyachar (2002: 498), sobre a microfinança comunitária como "low-cost Pinktertons" que obrigam à disciplina financeira.

21 Mais informação sobre o Kganya Group pode ser encontrada em <www.kganya.co.za>. Sobre as contas bancárias, ver <www.fnb.co.za/FNB/content/personal/banking/transmission/kganyaCard. $\mathrm{scml}>$.

22 Prémio em 2006. 
funerários e muitas outras tarefas de que as sociedades mútuas de funeral por norma se encarregam. Embora lhe tomasse muito tempo, o padre estava muito satisfeito com este plano funerário. Em todo o caso, quase todas estas tarefas eram cumpridas e a colaboração com a Kganya funcionava de forma muito eficaz. O facto de a ZCC ter o seu próprio fundo de maneio também ajudava a fazer frente a alguns casos. O padre deu o exemplo da morte após doença prolongada: a pessoa teria de estar hospitalizada durante um longo período de tempo e falhava mais de dois pagamentos. Se isso acontecesse, depois de a pessoa falecer, a seguradora não pagaria porque a apólice tinha caducado.

No sector dos seguros, a colaboração entre a ZCC e a African Life é reconhecida como o melhor exemplo de como contratar seguros com os pobres, na sua maioria africanos. A maior vantagem deste plano é que várias tarefas organizacionais são levadas a cabo por membros da ZCC, o que limita os custos administrativos pagos pela seguradora. Mas mesmo á́, como o fundador deste programa me explicou, o custo administrativo excedia o prémio de risco numa proporção de $3: 1$. Os custos administrativos são três vezes superiores aos custos das compensações. Isto significa que, mesmo num projecto que as seguradoras consideram um êxito, o grosso do prémio é usado em despesas administrativas e de infra-estruturas, não em compensações de riscos cobertos pelas apólices.

\section{CONCLUSÃO: RISCO E DESIGUALDADE}

Os riscos associados à desigualdade e à pobreza, na África do Sul especialmente relacionados com a violência, o HIV/SIDA e o desemprego, não eram tão problemáticos para as seguradoras como eu esperava. Em vez disso, os custos eram um obstáculo muito maior quando as companhias tentavam contratar apólices com os mais pobres e a classe média-baixa. As apólices pequenas, relativamente acessíveis, traduzem-se numa larga proporção de despesas administrativas: o prémio do risco é limitado de maneira a tornar as apólices mais acessíveis, o que aumenta a porção do prémio usada para cobrir as despesas. Para além disso, os clientes mais pobres - devido à sua exposição a maiores incertezas - cessam as suas apólices mais frequentemente.

As definições actuariais dos custos e dos níveis de risco seguem linhas surpreendentes. Não pretendo, de maneira alguma, pôr em causa os avanços fantásticos da ciência actuarial e a sua preciosa contribuição para o sector dos seguros e para o Estado-providência. Em vez disso, inspirado pela análise histórica e social da construção do risco formulada por Ewald (1986, 2002), defendo que os riscos para as seguradoras são muito diferentes dos riscos a que os mais pobres e a classe média-baixa estão expostos, e esta discrepância traduz-se em custos elevados. Estes custos significam que as seguradoras (ainda) não são suficientemente bem sucedidas na conversão destes riscos idiossincráticos em 
riscos colectivos. Custos elevados e baixo nível de riscos cobertos, pelo menos da perspectiva das seguradoras, são uma consequência da grande desigualdade que existe na África do Sul contemporânea. Aquilo que as seguradoras definem como custos é, em grande medida, o resultado da incapacidade de abranger os muitos riscos a que os clientes mais pobres estão expostos. Isto limita grandemente a capacidade dos mais pobres e da classe média-baixa para gerirem os muitos riscos e perigos a que estão sujeitos. Ao que tudo indica, as grandes desigualdades na África do Sul tornam difícil assegurar, e assim compensar, os mais pobres perante perdas e adversidades. Este caso sugere que os seguros na África do Sul (ainda) encontram um grande obstáculo nas desigualdades da era industrial e não tanto naquilo que Beck (1992 [1986]) identificou como os riscos da modernidade reflexiva. Para as seguradoras, os problemas que enfrentam não se interligam tanto com os riscos opacos, globais e provocados pelo homem, característicos da modernidade reflexiva identificada por Beck, mas mais com os riscos associados às desigualdades da era industrial.

Simultaneamente, contudo, corroborando o argumento de Beck em relação à sociedade de risco, a individualização realmente acontece, na medida em que a boa vontade que leva vizinhos, parentes e outras redes sociais a apoiar os mais necessitados tem vindo a diminuir (Beck 1992 [1986]: 93). Ao adquirirem seguros, os clientes tentam diminuir os riscos através de grandes instituições e limitar o fardo das relações de reciprocidade.

As dinâmicas de inclusão e exclusão também estão presentes na interacção da burocracia com as redes sociais (informais). As seguradoras sul-africanas são grandes empresas que operam num mercado global e, para reduzir custos, contam cada vez mais com soluções tecnológicas, como sofisticados call centers nacionais e outras técnicas administrativas e organizacionais de grande complexidade. Na sua tentativa de chegar aos menos abastados da sociedade, o capital social das seguradoras é crucial. Laços de confiança, normas e valores comuns e redes sociais densas - como Putnam (2000) define capital social tornaram-se recursos para ter acesso aos mais pobres, uma noção ainda mais central na definição de capital social de Bourdieu (1984). Em vez de assentarem em dispendiosas infra-estruturas financeiras, as seguradoras usam todo o tipo de redes comunitárias para ganhar acesso a esse segmento, sejam elas redes de vizinhança, sociedades mútuas de funerais, ou igrejas. A posição socioeconómica daqueles que detêm capital social pode deteriorar-se quando as seguradoras obrigam os mediadores a situações que parecem quase de escravatura. Tudo isto piora quando os clientes pagam prémios por apólices que não podem suportar ou de que nem precisam e quando os procedimentos burocráticos impossibilitam que se consiga receber qualquer compensação. $\mathrm{Na}$ tentativa de limitar os custos, as seguradoras colocam os mediadores e outros intermediários numa situação em que se arriscam a perder o seu capital social. Ao terem de usar estratégias agressivas para venderem as suas 
apólices, de forma a ganharem a vida, os correctores de seguros põem em risco as suas relações com vizinhos, membros da mesma congregação, familiares, etc. Quando os clientes falam sobre a moralidade dos seguros, fazem-no muitas vezes nos termos destas relações. Ao passo que nos Estados Unidos a questão moral se prendia com a determinação do preço de uma vida (Zelizer 1978) ou o preço do valor sentimental de uma criança (Zelizer 1994), a moralidade dos seguros na África do Sul assenta no seu compromisso com as relações sociais. Os seguros eram imorais quando arruinavam as relações entre os mediadores e potenciais clientes ou entre clientes e os seus dependentes.

Os mediadores não conseguem usar eficazmente as suas redes sociais para ajudar os clientes a receber efectivamente as compensações. Aqui, a tensão entre redes de inclusão e burocracias de exclusão revela-se de forma flagrante. As seguradoras confiam no capital social dos seus mediadores ou organizações intermediárias para a inclusão, mas privilegiam procedimentos burocráticos que excluem aqueles que, devido à sua posição socioeconómica bem como à natureza destes procedimentos e regulamentos, não conseguem receber a compensação. Só a Zion Christian Church parece conseguir ajudar de forma mais substancial, o que se deve à sua forte hierarquia e procedimentos burocráticos, já de si muito semelhantes aos das seguradoras.

O perigo que se revela é o de os clientes darem por si no "vácuo dos seguros". A segurança social assegurada pelas relações sociais informais está sob pressão. O declínio da segurança social com base nas relações pessoais é agravado pelos seguros de duas formas: em primeiro lugar, as companhias de seguros oferecem uma alternativa às relações de reciprocidade, já que, em vez de ser sobrecarregada com as exigências dos vizinhos, amigos ou familiares, uma pessoa pode fazer uma apólice; em segundo lugar, as seguradoras tentam ganhar acesso aos clientes, muitas vezes, à custa do capital social, especialmente do mediador. Por outro lado, devemos perguntar-nos se os seguros comerciais conseguem substituir a segurança baseada nas relações sociais informais. Quando as empresas falham no cumprimento das suas obrigações face aos clientes, estes podem nunca mais vir a ser capazes de regressar à rede social informal que deixaram para trás. Pode muito bem acontecer que a globalização dos seguros e a sua crescente acessibilidade para os mais pobres crie um vácuo dos seguros, tanto no seguro comercial como noutras formas baseadas no capital social, o que agrava a desigualdade global. Resta saber se as inovações tecnológicas, tal como previstas por Prahalad, são suficientes para ultrapassar este problema. Caso não sejam, os seguros, ao contrário do que poderíamos esperar, podem vir a contribuir para a desigualdade e para agravar os riscos a que os mais pobres, em particular, estão expostos. 


\section{BIBLIOGRAFIA}

BÄHRE, E., 2007a, Money and Violence: Financial Self-Help Groups in a South African Township. Leiden, Brill Academic Publisher.

— $2007 \mathrm{~b}$, "Reluctant solidarity: death, urban poverty, and neighbourly assistance in South Africa", Ethnography, 8 (1): 33-59.

BANK, L., 1999, "Men with cookers: transformations in migrant culture, domesticity and identity in Duncan Village, East London”, Journal of Southern African Studies, 25: 393 $-416$.

BBC, 2003, BBC news online, 13-5-2003, <www.bbc.co.uk/2/hi/africa/3024021.stm>.

BECK, U. 1992 [1986], Risikogesellschaft: Auf dem Weg in eine andere Moderne. Frankfurt a. M., Suhrkamp.

BIGGART, Nicole Woolsey, 1989, Charismatic Capitalism: Direct Selling Organizations in America. Chicago, University of Chicago Press.

BOURDIEU, P., 1984, Distinction: A Social Critique on the Judgement of Taste. Londres, Routledge. BROWN, M.J., 1998, "Preparing social work students for a corrupt work environment", Social Work, 34: 422-424.

BURKE, T., 1996, Lifeboy Men, Lux Women: Commodification, Consumption, and Cleanliness in Modern Zimbabwe. Londres, Leicester University Press.

DELIUS, P., 1993, "Migrant organisation, the Communist Party, the ANC and the Sekhukhuneland revolt, 1940-1958”, em P.D.P. Bonner e D. Posel (orgs.), Apartheid's Genesis: 1935-1962. Braamfontein, Joanesburgo, Ravan Press e Witwatersrand University Press.

DERCON, S., 2002, "Income risk, coping strategies, and safety nets", The World Bank Research Observer, 17: 141-166.

DIETZ, A. J., e D. FOEKEN, 2001, “The crumbling of the African state system”, em G. Jijink e H. Knippenberg (orgs.), The Territorial Factor: Political Geography in a Globalising World. Amesterdão, Vossiuspress, 177-200.

ELYACHAR, J., 2002, “Empowerment money: the World Bank, non-governmental organizations, and the value of culture in Egypt", Public Culture, 14 (3): 493-513.

ERICSON, R. V., e A. DOYLE, 2004, "Catastrophe risk, insurance and terrorism”, Economy and Society, 33 (2): 135-173.

EWALD, F., 1986, L'Etat Providence. Paris, Bernard Grasset.

— 2002 , “The return of Descartes's malicious demons: an outline of a philosophy of precaution”, em T. Baker e J. Simon (orgs.), Embracing Risk: The Changing Culture of Insurance and Responsibility. Chicago, University of Chicago Press, 273-302.

KIERNAN, J.P., 1974, "Where Zionists draw the line: a study of religious exclusiveness in an African township", African Studies, 33 (2): 79-90.

LELIVElD, A., 1994, Social Security in Developing Countries: Operation and Dynamics of Social Security Mechanisms in Rural Swaziland. Amesterdão, Tinbergen Institute Research Series.

_ 1997 , "The effects of restrictive South African migrant labor policy on the survival of rural households in Southern Africa: a case study from rural Swaziland", World Development, 25: 1839-1849.

NIENABER, P., 2005, "An industry under Siege", discurso inaugural do provedor de Justiça dos seguros de longa duração na Reunião Geral Anual, Cidade do Cabo, 18 de Novembro. 
NIENABER, P., e J. PREISS, 2006, "Funeral insurance: a perception from the Office of the Ombudsman for Long-term Insurance”, South African Mercantile Law Journal, 18: 291.

PORTEOUS, D., 2005, "The access frontier: an approach and tool in making markets work for the poor", documento financiado pela comissão política da DFID, disponível em $<$ http://www.bankablefrontier.com/assets/access-frontier-as-tool.pdf $>$.

PUTNAM, Robert D., 2000, Bowling Alone: The Collapse and Revival of American Community. Nova Iorque, Simon and Schuster.

PRAHALAD, C. K., 2004, Fortune at the Bottom of the Pyramid: Eradicating Poverty through Profits. Upper Saddle River, Wharton School Publishing.

SAGNER, A., e R.Z. MTATI, 1999, "Politics of pension sharing in urban South Africa", Ageing and Society, 19: 393-416.

SHARP, J.S., e A.D. SPIEGEL, 1985, "Vulnerability to impoverishment in South African rural areas: the erosion of kinship and neighborhood as social resources", Africa, 55: 133-152 .

THOMSON, R., e D. POSEL, 2002, "The management of risk by burial societies in South Africa", South African Actuarial Journal, 2: 83-127.

Von BENDA-BECKMANN, F., e K. Von BENDA-BECKMANN, 1994, "Coping with Insecurity", Focaal, 22/23: 7-31.

ZELIZER, V. A., 1978, "Human values and the market: the case of life insurance and death in 19th-Century America”, The American Journal of Sociology, 84 (3): 591-610.

—, 1994, Pricing the Priceless Child: The Changing Social Value of Children. Princeton, Princeton University Press.

Inclusive networks and exclusive bureaucracies: risks and commercial insurance for the South African poor - Erik Bähre - Leiden University, Países Baixos; London School of Economics, Reino Unido • ebaehre@fsw.leidenuniv.nl

Recently, large-scale South African companies are establishing a myriad of policies that aim to incorporate the previously excluded, mostly non-White, poor and middle classes. Here I examine definitions of risks and costs, as well as the attempt to save costs by relying on social capital among the poor. This casts a new light on lively debates on risk, inequality, and social capital. Research among clients living in the townships of Cape Town, as well as among insurance brokers, actuaries, and others involved in the world of insurance, reveal how policy costs are directly related to the many risks and adversities that the poor are exposed to. It reveals how insurers mobilize social capital to gain access to new markets - sometimes with disastrous consequences - and simultaneously have complex bureaucracies that make it very difficult for clients to submit claims successfully. This study counter-intuitively suggests that the rapid expansion of insurance could aggravate risks that the poor are exposed to and could increase inequalities.

KEYWORDS: South Africa, insurance policies, risk, poverty, social networks, marketing. 